\title{
Deep South China Sea circulation
}

\author{
Guihua Wang, ${ }^{1,2}$ Shang-Ping Xie, ${ }^{2,3}$ Tangdong Qu, ${ }^{2}$ and Rui Xin Huang ${ }^{4}$
}

Received 28 December 2010; accepted 26 January 2011; published 1 March 2011.

[1] The analysis of an updated monthly climatology of observed temperature and salinity from the U.S. Navy Generalized Digital Environment Model reveals a basinscale cyclonic circulation over the deep South China Sea (SCS). The cyclonic circulation lies from about $2400 \mathrm{~m}$ to the bottom. The boundary current transport of the cyclonic circulation is around 3.0 Sv. Our results suggest that the cyclonic circulation is mainly forced by the Luzon overflow, with bottom topography playing an important role. The structures of potential temperature, salinity, and potential density in the deep SCS are consistent with the existence of the cyclonic circulation. Specifically, low salinity water is found in the interior region west of Luzon Island, and surrounded by saline Pacific water in boundary current regions to the north, west and southwest. Our results show the potential density distribution and the corresponding cyclonic circulation in deep SCS are primarily controlled by salinity variations in the deep basin. Citation: Wang, G., S.-P. Xie, T. Qu, and R. X. Huang (2011), Deep South China Sea circulation, Geophys. Res. Lett., 38, L05601, doi:10.1029/2010GL046626.

\section{Introduction}

[2] The South China Sea (SCS) is the largest deep semienclosed marginal sea in the western Pacific, bounded by the Asian continent, Philippine Islands, and Great Sunda Islands. The deepest water is confined to a bowl-shaped trench with the maximum depth around $5560 \mathrm{~m}$ [Wyrtki, 1961]. The Luzon strait is the only deep channel connecting with the open oceans, and the deepest sill in the Strait is around $2400 \mathrm{~m}$ [Qu et al., 2006]. The water exchange between the SCS and the Pacific through Luzon strait is of importance for the SCS circulation and heat and salt budgets [Qu et al., 2009].

[3] The SCS is a completely isolated basin under $2400 \mathrm{~m}$ with no direct water exchange to the surrounding oceans (Figure 1a) [also see Qu et al., 2006]. However, its deep water property is very similar to that of the Pacific at depths around $2400 \mathrm{~m}$ [e.g., Broecker et al., 1986; Qu, 2002]. It has been interpreted as evidence for the existence of an overflow. Driven by a persistent baroclinic pressure gradient, the colder and higher density Pacific water sinks to the SCS

\footnotetext{
${ }^{1}$ State Key Laboratory of Satellite Ocean Environment Dynamics, Second Institute of Oceanography, Hangzhou, China.

${ }^{2}$ International Pacific Research Center, University of Hawaii at Manoa, Honolulu, Hawaii, USA.

${ }^{3}$ Physical Oceanography Laboratory, Ocean University of China, Qingdao, China. USA.

${ }^{4}$ Woods Hole Oceanographic Institution, Woods Hole, Massachusetts,

Copyright 2011 by the American Geophysical Union. 0094-8276/11/2010GL046626
}

after it crosses the Luzon Strait [Wyrtki, 1961; Qu et al., 2006; $L i$ and $Q u, 2006]$. The modeled meridional overturning structure with an opening of the northern SCS supports the sinking of the Pacific water through the Luzon strait [Wang et al., 2004; Liu et al., 2008]. The overflow transport was estimated to be $0.7-3.0 \mathrm{~Sv}\left(1 \mathrm{~Sv}=10^{6} \mathrm{~m}^{3} \mathrm{~s}^{-1}\right)$ based on different observations and model results [e.g., Wang, 1986; Liu and Liu, 1988; Qu et al., 2006; Tian et al., 2006]. Qu et al. [2006] suggested that upon entering the SCS the overflow water turns northwestward, forming a basin-scale cyclonic circulation in the deep SCS, a speculation consistent with temperature, oxygen, and sediment distributions. According to the classical theory, the closure of cyclonic circulation requires a narrow western boundary current. Based on the hydraulic theory and oxygen utilization [e.g., Broecker et al., 1986; Qu et al., 2006], the residence time of the deep SCS water is relatively short, most likely between 30 and 100 years. The fast replenishment of deep SCS water implies the deep water must be pulled up to the upper layer through strong diapycnal mixing [Tian et al., 2009], indicating its potentially important contribution to the upper layer circulation, regional air-sea interaction, and heat and freshwater budgets in the tropical Indian and Pacific Oceans [Qu et al., 2009].

[4] Due to the lack of observations and inadequate quality control, detailed structures of water properties and circulation in the deep SCS have not been mapped out and described adequately. This study attempts to quantitatively describe the deep SCS circulation using an updated U.S. Navy temperature and salinity climatology, which resolves the temperature and salinity structures of the deep ocean reasonably well [Carnes, 2009]. Specifically, the salinity climatology is of high accuracy. This enables us to show that potential density structures in the deep basin are dominated by salinity variations, in contrast to previous studies that often infer salinity from temperature observations based on the least-square fit of a straight line to the adjacent Pacific data [Qu et al., 2006].

\section{Data and Methods}

[5] The U.S Navy Generalized Digital Environment Model (GDEM-Version 3.0) monthly climatology of observed temperature and salinity has a horizontal resolution of $0.25^{\circ} \times$ $0.25^{\circ}$. It has 78 standard depths from surface to $6600 \mathrm{~m}$, with a vertical resolution varying from $2 \mathrm{~m}$ at the surface to $200 \mathrm{~m}$ below $1600 \mathrm{~m}$. The GDEM-Version 3.0 was derived from the temperature and salinity profiles extracted from the Mater Oceanographic Observational Data Set edited at the Naval Research Laboratory (NRL). The NRL manually examined all the profiles within groups covering small geographic regions and short seasonal or monthly time periods in order to remove erroneous profiles. Compared to its previous versions, the GDEM-Version 3.0 has shown several significant 

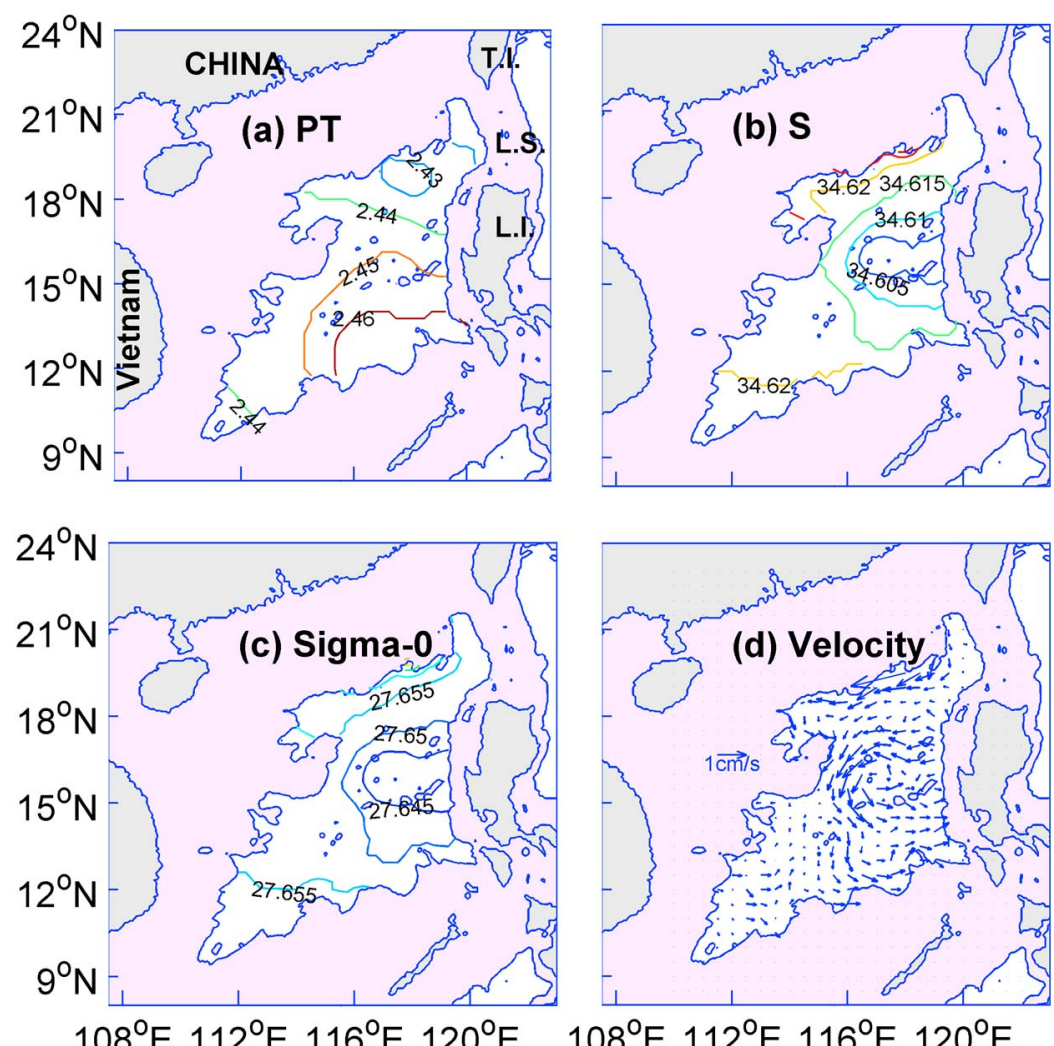

$108^{\circ} \mathrm{E} 112^{\circ} \mathrm{E} 116^{\circ} \mathrm{E} 120^{\circ} \mathrm{E} \quad 108^{\circ} \mathrm{E} 112^{\circ} \mathrm{E} 116^{\circ} \mathrm{E} 120^{\circ} \mathrm{E}$

Figure 1. (a) Potential temperature $\left({ }^{\circ} \mathrm{C}\right)$, (b) salinity, (c) potential density $\sigma_{0}\left(\mathrm{Kg} \mathrm{m}^{-3}\right)$, and (d) geostrophic current $(\mathrm{cm} / \mathrm{s})$ at 3000 m. In Figure 1a, L.S.: Luzon Strait; L.I.: Luzon Island; T.I.: Taiwan Island.

improvements, which are relevant to our present study: 1) it corrected many erroneous thermal inversions, where denser water overlies lighter water; 2) it improved the gridding algorithm and eliminated interpolation across land boundaries, thus allowing us to define the fronts along the land better; 3 ) it archived the temperature and salinity in three decimal places, rather than two as in the earlier versions and the world ocean atlas (WOA). It has been shown that retaining 3 decimal places much improves the representation of salinity and density structure in the deep ocean. The data evaluation for global oceans was reported by Carnes [2009]. Comparison with previous water masses analysis [ $\mathrm{Li}$ et al., 2002; Qu et al., 2006] demonstrates that the GDEM can capture a detailed salinity distribution in the deep SCS.

[6] We calculate the geotropic velocity from the GDEMVersion 3.0 using the thermal wind relation:

$$
\begin{aligned}
& u=u_{0}+\frac{g}{f \rho_{0}} \int_{z_{0}}^{z} \frac{\partial \rho}{\partial y} d z^{\prime} \\
& v=v_{0}-\frac{g}{f \rho_{0}} \int_{z_{0}}^{z} \frac{\partial \rho}{\partial x} d z^{\prime}
\end{aligned}
$$

where $(\mathrm{u}, \mathrm{v})$ and $(\mathrm{u} 0, \mathrm{v} 0)$ are geostrophic velocities at depth $\mathrm{z}$ and at a reference level $\mathrm{z}_{\mathrm{o}}$, respectively, $\mathrm{g}$ is the gravitational acceleration, $\rho$ is the water potential density, and $\rho_{0}$ is the characteristic water potential density. Here the reference velocity $\left(\mathrm{u}_{0}, \mathrm{v}_{0}\right)$ is set to be 0 at $2400 \mathrm{~m}$, representing the deepest sill depth of the Luzon Strait. The choice is based on the fact that flow near the bottom is usually much faster than above for the deep circulation. Thus the pressure gradient at $2400 \mathrm{~m}$ is relatively weak and can be approximately regarded as a level of no motion. The idea of selecting a level of no motion has been extensively used in study of abyssal circulation [e.g., Stommel and Arons, 1960; Speer and McCartney, 1992]. The general circulation pattern presented in this study is not sensitive to the choice of reference level.

\section{Results}

\subsection{Horizontal Distribution of Deep SCS Circulation}

[7] Figure 1 shows the potential temperature $(\Theta)$ and salinity distributions at $3000 \mathrm{~m}$. Water properties at this depth have relatively narrow ranges at $2.425<\Theta<2.465^{\circ} \mathrm{C}$ and $34.600<\mathrm{S}<34.630$. A prominent feature of potential temperature is the cold water in the northeastern corner of the basin. This cold water $\left(<2.43^{\circ} \mathrm{C}\right)$ appears to be part of the overflow water through the Luzon strait. Water from the Pacific can also be traced by temperature and density through the Luzon strait, as shown by $Q u$ et al. [2006, Figure 6]. It spreads along the northern and the western continental margins. The highest potential temperature is seen in the southeastern corner. Salinity distribution at $3000 \mathrm{~m}$ also shows a northwestward spreading of salty water along the northern boundary off southeast China and east of South Vietnam (Figure 1b). Low salinity water $(\mathrm{S}<34.605)$ is located west of Luzon island $\left(115^{\circ} \mathrm{E} \sim 118^{\circ} \mathrm{E}, 14.5^{\circ} \mathrm{N} \sim 16.5^{\circ} \mathrm{N}\right)$, a feature that has not been noted in the literature. The low salinity water may be formed by mixing dynamics: Salinity 

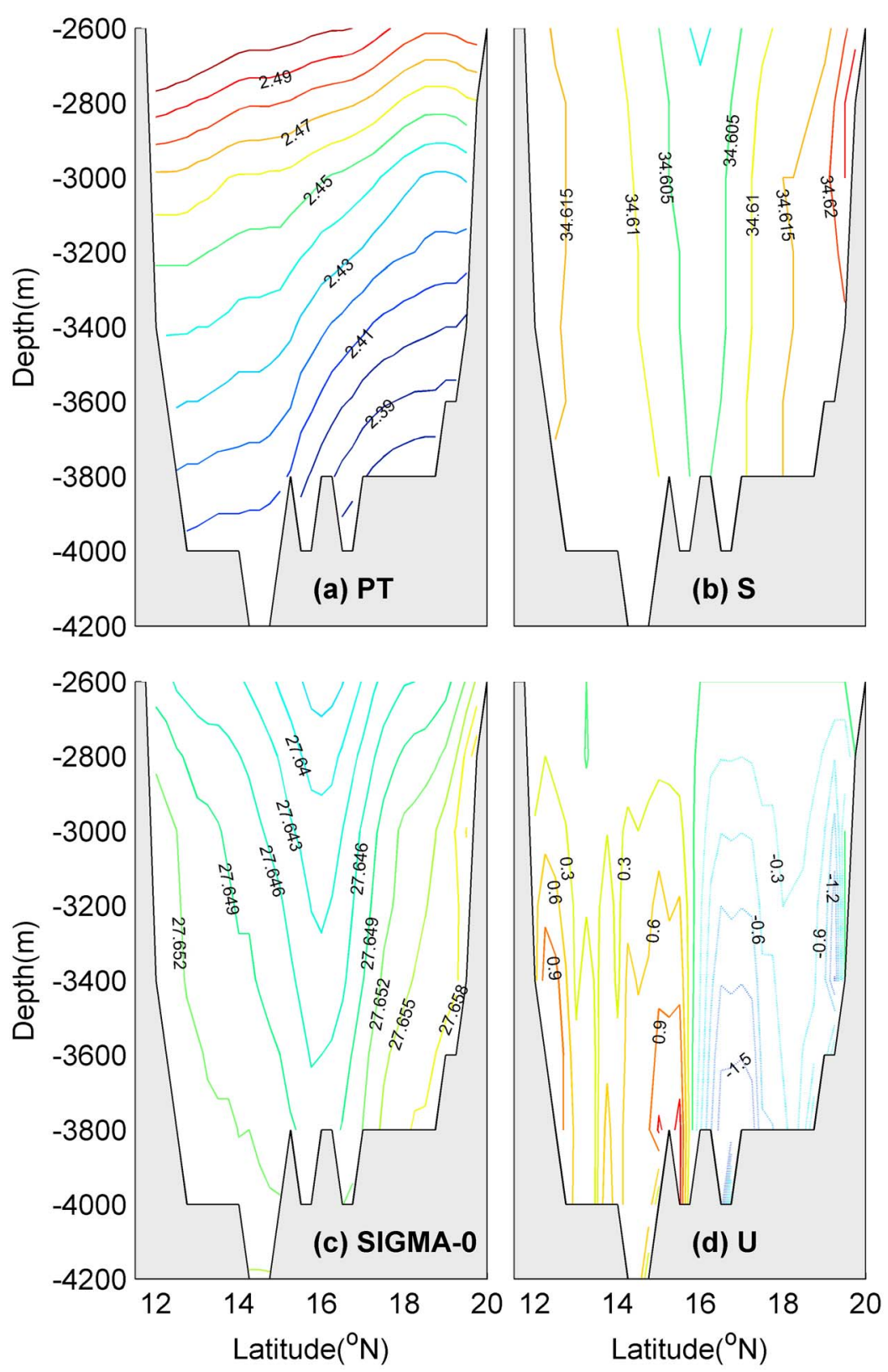

Figure 2. (a) Potential temperature $\left({ }^{\circ} \mathrm{C}\right)$, (b) salinity, (c) potential density $\sigma_{0}\left(\mathrm{Kg} \mathrm{m}^{-3}\right)$, and (d) geostrophic current $(\mathrm{cm} / \mathrm{s})$ along $117^{\circ} \mathrm{E}$. In Figure 2d, solid (dashed) lines are for positive (negative) values.

between 800-2000 $\mathrm{m}$ is lower than below $2000 \mathrm{~m}$ [Qu, 2002], suggesting relatively fresh in the intermediate layer of the SCS. Below $2000 \mathrm{~m}$, water is formed as a result of the counterbalance between advection and diffusion. Advection due to the intrusion of the Pacific water tends to enhance the salinity in the deep SCS. Diffusion resulting from the rough topography helps pull down more low salinity water into deep central SCS and freshen it. Both potential temperature and salinity distributions indicate that the deep layer circulation in the SCS is predominantly cyclonic, confirming the speculation of $Q u$ et al. [2006] based on a qualitative analysis of historical data.

[8] Potential density shows a similar pattern to salinity (Figure 1c), implying that the potential density in the deep SCS is dominated by salinity variations. High potential density water spreads along the continental margins cyclon- ically, while low potential density water is collocated with low salinity water west of Luzon (Figure 1b). This result is different from the earlier study of Qu et al. [2006]. The latter study identified the low potential density water in the southeastern corner because of the use of a linear empirical temperature/salinity relationship. The potential density gradient between the continental margins and the central SCS suggests a cyclonic circulation in the deep SCS relative to the $2400 \mathrm{~m}$. The strong gradient along the northwestern margin implies a strong boundary current.

[9] Based on the thermal wind relation, we calculate geostrophic flow at $3000 \mathrm{~m}$ (Figure 1d). The basin scale cyclonic circulation is evident, consistent with the potential density distribution. Strong westward, southward, and eastward currents are present along the northern, western, and southern continental margins, with the maximum speeds 

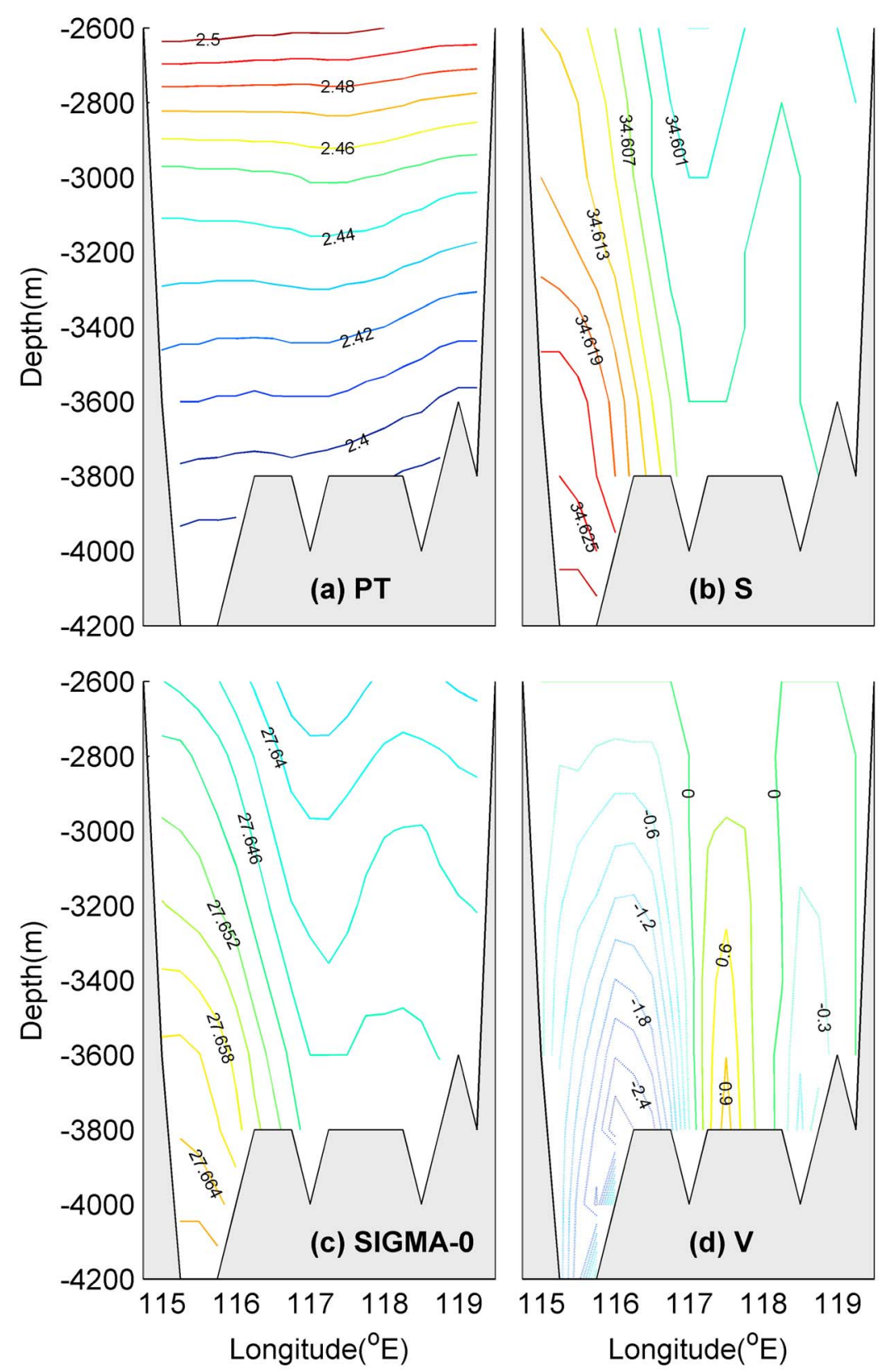

Figure 3. (a) Potential temperature $\left({ }^{\circ} \mathrm{C}\right)$, (b) salinity, (c) potential density $\sigma_{0}\left(\mathrm{Kg} \mathrm{m}^{-3}\right)$, and (d) geostrophic current $(\mathrm{cm} / \mathrm{s})$ along $16^{\circ} \mathrm{N}$. In Figure $3 \mathrm{~d}$, solid (dashed) lines are positive (negative) values.

at $3000 \mathrm{~m}$ reaching $1.94,1.91$ and $0.44 \mathrm{~cm} / \mathrm{s}$, respectively. The basin scale cyclonic circulation does not extend to the southwestern corner, where there seems to exist a separate weak cyclonic circulation. The exact cause of this weak cyclonic circulation is unclear but seamounts around $115^{\circ} \mathrm{E}$, $14^{\circ} \mathrm{N}$ may play a role in separating the southwestern subbasin cyclonic circulation from the main basin-scale cyclonic circulation.

\subsection{Vertical Distribution of Deep SCS Circulation}

[10] Figure 2 shows vertical structures of potential temperature, salinity, potential density, and zonal velocity along $117^{\circ} \mathrm{E}$ in the deep SCS. The uplift of isotherms toward the north suggests a bottom intensified boundary current that carries the dense Pacific water westward along the northern boundary (Figure 2a). The salinity distribution suggests the same westward current along the northern boundary as well as an eastward current along the southern boundary (Figure $2 b$ ). Potential density (Figure $2 c$ ) shows a pattern similar to salinity, with the dense Pacific water along the northern and southern boundaries and light SCS water in the central basin. Geostrophic current (Figure 2d) indeed shows a westward current north of $16^{\circ} \mathrm{N}$ and an eastward current south of $16^{\circ} \mathrm{N}$. Both the westward and the eastward currents have two cores: one clings to the northern or southern boundary, and the other in the central basin. The currents in Figure $2 \mathrm{~d}$ match those in Figure 1d well. The formation mechanism for the central core may be related to the seamounts there: the bottom intensified mixing may induce an upwelling over the seamounts but a downwelling 


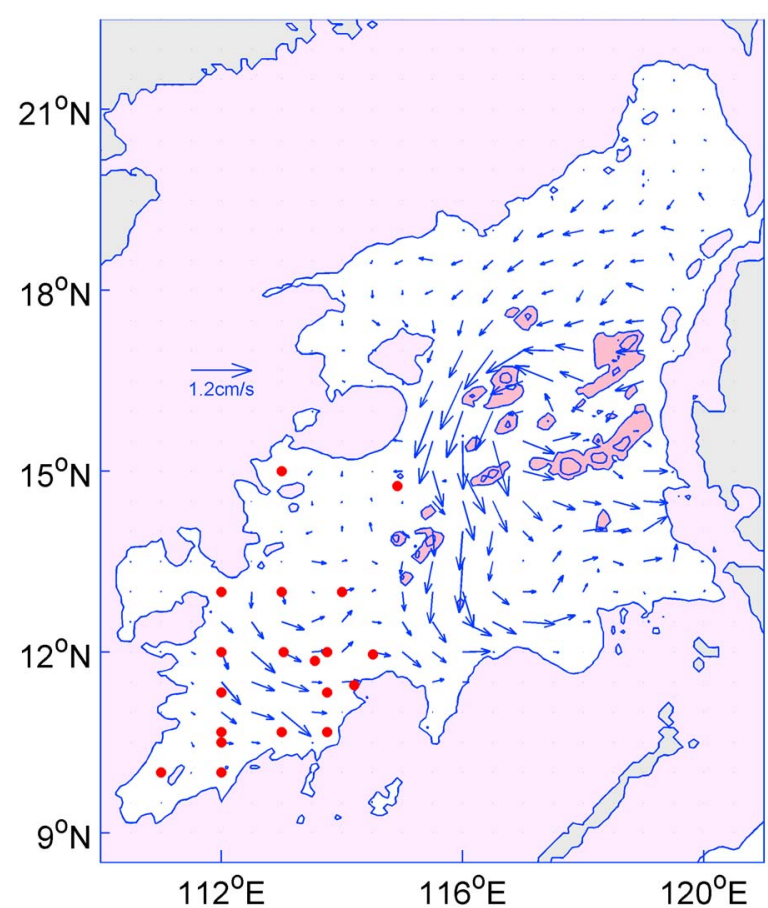

Figure 4. Vertical-averaged geostrophic current $(\mathrm{cm} / \mathrm{s})$ from $2400 \mathrm{~m}$ to the bottom. The light pink shading indicates water depths shallower than $2400 \mathrm{~m}$. The dark pink shading indicates sea mountains shallower than $3600 \mathrm{~m}$. The red solid dots denote stations where oxygen exceeds $2.15 \mathrm{~mL}$ $\mathrm{L}^{-1}$ at $3000 \mathrm{~m}$ layer.

in their nearby regions, and in the sense of geostrophy, this implies a stronger boundary current around the seamounts [Huang and Jin, 2002].

[11] Figure 3 shows potential temperature, salinity, potential density, and the meridional current on a zonal section at $16^{\circ} \mathrm{N}$. West of $117^{\circ} \mathrm{E}$, there exists a salinity front, with salinity decreasing from 34.625 at the western continental margin to 34.605 in the central SCS (Figure 3b). The salinity front results in a similar front in potential density (Figure 3c). At $3500 \mathrm{~m}$, potential density decreases from $27.658 \mathrm{~kg} \mathrm{~m}^{-3}$ in the west to $27.646 \mathrm{~kg} \mathrm{~m}^{-3}$ in the east along the front. Associated with this front structure, there is a strong southward current along the western boundary (Figure 3d), where its maximum velocity can reach $2.7 \mathrm{~cm} / \mathrm{s}$ (Figure $3 \mathrm{~d}$ ). The uplifted isohalines and isopycnals from $117^{\circ} \mathrm{E}$ to $118.5^{\circ} \mathrm{E}$ are associated with a northward current, while the downward isohalines and isopycnals west of $118.5^{\circ} \mathrm{E}$ indicate a southward current (Figure 3d).

[12] The above results show a clear basin scale cyclonic circulation, with westward, southward, and eastward currents along the northern, western and southern margins, respectively. The potential temperature, salinity and potential density distributions show consistent patterns from $2400 \mathrm{~m}$ to the bottom, leading to a quasi-barotropic circulation in the deep SCS (Figures $2 \mathrm{~d}$ and $3 \mathrm{~d}$ ). Over the entire deep SCS, horizontal current reaches its maximum speed of $2.44,3.23$ and $1.42 \mathrm{~cm} / \mathrm{s}$ along the northern, western, and southern boundaries, respectively.

[13] Figure 4 shows vertically averaged velocity from $2400 \mathrm{~m}$ to the bottom. The basin scale cyclonic circulation is robust, with the vertically averaged velocity reaching 1.09 , 1.36 and $0.65 \mathrm{~cm} / \mathrm{s}$ along the northern, western, and southern regimes, respectively. Generally, the bottom flow is much stronger, which is also obvious in Figures $2 \mathrm{~d}$ and $3 \mathrm{~d}$. The result is consistent with the classic theory of abyssal circulation and earlier observations as well [e.g., Stommel and Arons, 1960]. Embedded in the basin scale cyclonic circulation, a stronger sub-basin scale cyclonic circulation is seen around the seamounts in the central SCS. Topographyinduced abyssal circulation and jets have been studied previously [e.g., Kuo, 1974; Mizuta and Masuda, 1998]. Strong southward abyssal flow along $116^{\circ} \mathrm{E}$ is also suggestive of topographic effects of central SCS seamounts, whose mechanism needs further investigations. West of $116^{\circ} \mathrm{E}$, a separate weak cyclonic circulation in the southwestern basin is especially clear in the vertical mean (Figure 4). The available oxygen data archived in the World Ocean Database (WOD09) show high oxygen $\left(>2.15 \mathrm{~mL} \mathrm{~L}^{-1}\right)$ on the margins of the separate cyclonic circulation in the southwestern basin (Figure 4), indicating the abyssal water also comes from the Pacific [ $L i$ and $Q u, 2006]$.

[14] The boundary currents on the northern, western and southern sides are westward, southward, and northward, respectively. To calculate their transports, three sections are chosen: north of $16^{\circ} \mathrm{N}$ along the meridional section at $117^{\circ} \mathrm{E}$, west of $117^{\circ} \mathrm{E}$ along the zonal section at $16^{\circ} \mathrm{N}$, and south of $16^{\circ} \mathrm{N}$ along the meridional section at $117^{\circ} \mathrm{E}$. The northern, western, and southern boundary current transports are 3.13 (westward), 2.92 (southward), and 3.11 (eastward) $\mathrm{Sv}$ respectively. These values are fairly close to an independent estimate $(2.5 \mathrm{~Sv})$ of Luzon deepwater overflow [Qu et al., 2006], supporting the earlier speculation that the overflow may provide a source for the basin scale deep SCS cyclonic gyre. The slightly high values may indicate the recirculation in the deep SCS or entrainment of upper ocean water. Seasonal variability is not significant although these transports are slightly stronger during summer from June to August than the rest of the year.

\section{Summary and Discussions}

[15] This study has provided the first quantitative description of the deep SCS circulation and its concomitant boundary current system. Our results suggest that the abyssal cyclonic circulation is mainly driven by the Luzon overflow, and that its detailed structures may be strongly influenced by bottom topography. Low salinity water is found west of Luzon, consistent with the notion that saline Pacific water is transported by the boundary current system. The potential density field in the SCS shows a pattern similar to salinity, suggesting that the cyclonic circulation in the deep SCS is primarily controlled by salinity variations.

[16] The wind-driven upper layer circulation in the SCS is also cyclonic [Wyrtki, 1961]. The relationship between the wind-driven upper-layer, and overflow-driven deep-layer circulations is an interesting issue to address. As suggested by several earlier studies [e.g., Qu et al., 2009], the SCS deep circulation may contribute to the SCS Throughflow, through enhanced vertical mixing [e.g., Tian et al., 2009]. Although the uncertainties of GDEM data and temporal change in the SCS abyssal circulation cannot be evaluated at 
this point because the original profiles are not available, there are interesting topics for future studies.

[17] Acknowledgments. G. Wang was supported by the National Basic Research Program (2007CB816003) and the National Natural Science Foundation of China (40976017, 40730843); S.-P. Xie by the US National Foundation (NSF), the Changjiang Scholar and Qianren Programs; T. Qu by NSF (OCE10-29704). We appreciate useful comments from two anonymous reviewers.

\section{References}

Broecker, W. S., W. C. Patzert, J. R. Toggweiler, and M. Stuvier (1986), Hydrography, chemistry, and radioisotopes in the southeast Asian basin, J. Geophys. Res., 91, 14,345-14,354, doi:10.1029/JC091iC12p14345.

Carnes, M. R. (2009), Description and evaluation of GDEM-V3.0, NRL Rep. NRL/MR/7330-09-9165, Nav. Res. Lab., Washington, D. C.

Huang, R. X., and X.-Z. Jin (2002), Deep circulation in the South Atlantic induced by bottom-intensified mixing over the Mid-Ocean Ridge, J. Phys. Oceanogr., 32, 1150-1164, doi:10.1175/1520-0485(2002) 032<1150:DCITSA $>2.0 . \mathrm{CO} ; 2$

Kuo, H. H. (1974), The effect of bottom topography on the stationary planetary flow on a sphere, Deep Sea Res. Oceanogr. Abstr., 21, 933-945, doi:10.1016/0011-7471(74)90026-6.

Li, L., and T. Qu (2006), Thermohaline circulation in the deep South China Sea basin inferred from oxygen distributions, J. Geophys. Res., 111, C05017, doi:10.1029/2005JC003164.

Li, L., F. Li, J. Su, and J. Xu (2002), Analysis on water masses in the South China Sea in summer and winter of 1998, Oceanol. Limnol. Sin., 33(4), 393-401.

Liu, C.-T., and R.-J. Liu (1988), The deep current in the Bashi Channel, Acta Oceanogr. Taiwan., 20, 107-116.

Liu, C., Y. Du, Q. Zhang, and D. Wang (2008), Seasonal variation of subsurface and intermediate water masses in the South China Sea, Oceanol. Limnol. Sin., 39(1), 55-64.

Mizuta, G., and A. Masuda (1998), Three-dimensional structure of thermohaline circulation steered by bottom topography, J. Phys. Oceanogr., 28,
1979-1998, doi:10.1175/1520-0485(1998)028<1979:TDSOTC $>2.0$. $\mathrm{CO} ; 2$.

Qu, T. (2002), Evidence for water exchange between the South China Sea and the Pacific Ocean through the Luzon Strait, Acta Oceanol. Sin., 21(2), 175-185.

Qu, T., J. B. Girton, and J. A. Whitehead (2006), Deepwater overflow through Luzon Strait, J. Geophys. Res., 111, C01002, doi:10.1029/ 2005JC003139.

Qu, T., T. Song, and T. Yamagata (2009), An introduction to the South China Sea throughflow: Its dynamics, variability, and implication for climate, Dyn. Atmos. Oceans, 47, 3-14, doi:10.1016/j.dynatmoce.2008.05.001

Speer, K. G., and M. S. McCartney (1992), Bottom water circulation in the western North Atlantic, J. Phys. Oceanogr., 22, 83-92, doi:10.1175/ 1520-0485(1992)022<0083: BWCITW $>2.0$.CO 2 .

Stommel, H., and A. B. Arons (1960), On the abyssal circulation of the World Ocean-II. An idealized model of the circulation pattern and amplitude in oceanic basins, Deep Sea Res., 6, 217-233.

Tian, J., Q. Yang, X. Liang, L. Xie, D. Hu, F. Wang, and T. Qu (2006), Observation of Luzon Strait transport, Geophys. Res. Lett., 33, L19607, doi:10.1029/2006GL026272.

Tian, J., Q. Yang, and W. Zhao (2009), Enhanced diapycnal mixing in the South China Sea, J. Phys. Oceanogr., 39, 3191-3203, doi:10.1175/ 2009JPO3899.1.

Wang, D., X. Liu, W. Wang, Y. Du, and W. Zhou (2004), Simulation of meridional overturning in the upper layer of the South China Sea with an idealized bottom topography, Chin. Sci. Bull., 49(7), 740-747.

Wang, J. (1986), Observation of abyssal flows in the northern South China Sea, Acta Oceanogr. Taiwan., 16, 36-45.

Wyrtki, K. (1961), Physical oceanography of the southeast Asian waters, NAGA Rep. 2, 195 pp., Univ. of Calif., San Diego, La Jolla.

R. X. Huang, Woods Hole Oceanographic Institution, 266 Woods Hole Rd., Woods Hole, MA 02543, USA.

T. Qu and S.-P. Xie, International Pacific Research Center, University of Hawaii at Manoa, 1680 East West Rd., Honolulu, HI 96822, USA.

G. Wang, State Key Laboratory of Satellite Ocean Environment Dynamics, Second Institute of Oceanography, No. 36 Bao Shu Bei Rd., Hangzhou 310012, China. (guiha_wanggh@yahoo.com.cn) 